having seen any original or detailed account of the phenomena to which Mr. Webb alludes, I am unable to say whether they fulfil these theoretical conditions, but I believe that something more may be learned by means of careful observations specially directed to the elucidation of the questions I have suggested.

Woodside, Croydon, Oct. 23

$$
\text { W. MatTIEU WILIIAMS }
$$

\section{Pendulum Autographs}

IT may interest some of your readers to know that they can for themselves observe in the most accurate manner the motion of the compound pendulum described by $\mathrm{Mr} \mathrm{H}$. Airy* by merely attaching the ends of a fine thread to two points in the ceiling of a room, and suspending a leaden bullet by means of a second thread tied to the middle point of the former, so that the bullet may just escape the floor. Lay underneath a large sheet of white paper ruled with two dark lines at right angles to each other to correspond to the two axes of vibration. It is Mr. Airy's experiment with the hoop on an extended scale. The motion of the bullet, unimpeded by contact of pencil with paper, is graceful and accurate in the extreme.

Perhaps the most remarkable case is that in which the two points of suspension are taken about an inch apart, and the third about half an inch below them; the pendulum will now keep reversing its motion as uniformly as before, and apparently without any adequate cause, a matter of astonishment to the uninitiated spectator.

I believe the general equation to the path, including all the curves described, will be found to be $\sqrt{ } n \cos ^{-1} \frac{x}{a}=\sqrt{ } m \cos ^{-1} \frac{y}{b}$, where the particle starts from the point $(a, b)$ and is attracted to the axes of $X$ and $Y$ by forces $=-n y$ and $-n x x$ respectively.

Woolwich, Oct. 24

GEO, S. CARR

\section{Exogenous Structures in Coal Plants}

I CORDIALLY agree with your recommendation that discussion on the Exogenous Stems of the Coal Measures should cease for the present. It is evident that I shall not convince my two opponents, and they are as far as ever they were from convincing me. But I must request that in justice to me, you will allow me to enter a protest against the last paragraph of Prof. Dyer's article, in which he objects to my applying the term Protoplasmic to the cambium layer, and endeavours to show that I am two hundred years behind the age in my physiology. I cannot but think that Prof. Dyer, when he penned that paragraph, knew perfectly well in what sense I used that expression. I meant by it nothing more than is implied in the following sentence, taken from Prof. Balfour's “"Manual of Botany," p. 43, which certainly does not belong to the age of Grew :-

"External to the woody layers, and between them and the bark, there is a layer of mucilaginous semifluid matter, which is particularly copious in spring, and to which the name Cambium has been given. In this are afterwards found cells, called Cambium Cells, of a delicate texture, in which the protoplasm and primary utricle are conspicuous."

Fallowfield, Oct. 25

W. C. WILLIAMSON

** This correspondence must now close,-ED.

\section{Classification of Fruits}

IT seems from the numerous attempts that have been made that a philosophical classification of fruits is either unattainable or practically of very little value when attained. At any rate working botanists have, as a rule, discarded the majority of the carpological terms that are to be found in text-books as too cum. brous or too uncertain in their application. Among the latest attempts at simplification in the matter of the classification of fruits are those of my friends Prof. Dickson and Dr. M ${ }^{\circ} \mathrm{Nab}$ (see NATURE, vol. iv. p. 475). Both of these are open to some crilicism on matters of detail, but I can hardly expect you to accord me space to point out what I believe to be the merits or shortcomings of their respective schemes. I should also trespass too much on your courtesy and on the patience of your readers did I enter into any engthened explanation of the following scheme, in which I have adopted to some extent the nomenclature of Prof. Dickson

\footnotetext{
* See Nature, vol, iv pp. 310, 317.
}

and Dr. $M \circ N a b$, and which $I$ offer for consideration solely on the grounds of expediency and simplicity:-

\section{Classification of Monothalamic Fruits}

A. Ripe pericarp uniform

Fruits indehiscent

Fruits dehiscent

I. Nuts or Achrenocarps

II. Pods or Regmacarps.

B. Ripe pericarp of two or more layers of different substance * Seeds within a hardened
endocarp Seeds embedded in pulp" IV. Berries or Sarcocarps.

\section{Nats or Achienocarps}

WINGLESS-

Fruit of one carpel, or, if of more, apocarpous . . . . . . . . Achene

Fruit of more than one carpel

Carpels ultimately separate but inde-

hiscent . . . . . . Carcerule

Carpels inseparate

(Cremocarp).

Pericarp adherent to the seed : . Caryopsis.

Pericarp free from the seed, within a cupule . . . . . . . Glans.

Winged . . . . . . . . . . . Samara

Fruit of one carpel

$$
\text { II. Pods or Regmacarps }
$$

Opening by one suture . . . . Follicle two sutures. . . . . Legume transversely: : : : Lomentum

(Dichisma, $M \cdot N a b$ )

Fruit of more than one carpel Opening by pores or sutures

$$
\begin{aligned}
& \text { (Siliqua) } \\
& \text { (Regma) } \\
& \text { (Conceptaculum) } \\
& \text { Opening transversely. . . . . Pyxis, } \\
& \text { (Tryma, xc.) } \\
& \text { III. Stone-fruits or Pyrenocarps }
\end{aligned}
$$

$$
\text { IV. Berries or Sarcocarps }
$$

Seeds embedded in pulp . . . . Bacca

$$
\begin{aligned}
& \text { (Hesperidium) } \\
& \text { (Uva) } \\
& \text { (Pepo). }
\end{aligned}
$$

I believe that the foregoing arrangement will include most of the varieties of fruits and seed-vesseis, though, as in all similar cases, exceptional forms are not readily surted into their proper place; the fruit of such Cassias as $C$. Fistula, generally called a lomentum, is a case in point. For general purposes the varieties enclosed in brackets may well be omitted, save in the case of so well known and constantly used a term as siliqua, which, despite Prof. Dickson's veto, I think is too useful prac/ically to be lightly abandoned.

$$
\text { MaXWRLl T. Masters }
$$

\section{The Berthon Dynamometer}

A BSENCE from home, and many engagements, have prevented an earlier reply to "W. R.'s" letter in NATURE, October 5 . In my previous communication I believe I gave the address of the inventor, to whom I thought reference might naturally be made ; in order, however, to meet "W. R.'s" wish, I will explain the construction of the very simple but efficient instrument in question. It is merely a V gauge, formed of two pitces of thin brass converging at a very acute angle, and graduated along one of the edges; the divisions being viewed through a lens held in the

* The pericarp is here understood as including not only the ripened carpeliary wall, nut also any adjunct to it which in process of development may from the carpel or from the seed itself. 